COMMENTARY ON COVID-19 AND THE Food SyStem

\title{
"Informalization" of food vending in China: From a tool for food security to employment promotion
}

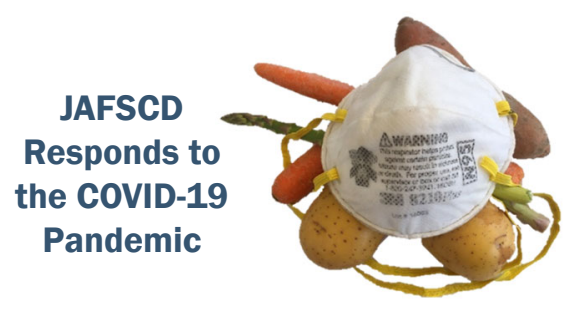

\author{
Taiyang Zhong a* \\ Nanjing University \\ Steffanie Scott ${ }^{b}$ \\ University of Waterloo
}

Submitted June 8, 2020 / Published online June 12, 2020

Citation: Zhong, T., \& Scott, S. (2020). "Informalization" of food vending in China: From a tool for food security to employment promotion. Journal of Agriculture, Food Systems, and

Community Development, 9(4), 135-137. https://doi.org/10.5304/jafscd.2020.094.006

Copyright (C) 2020 by the Author. Published by the Lyson Center for Civic Agriculture and Food Systems. Open access under CC-BY license.

\begin{abstract}
The central government of China required local governments to allow street food vending on May 27, 2020 , which is essentially a policy of "informalization" in urban food governance. Before this, some local governments such as Nanjing Municipal Government had already relaxed the implementation of regulations for street food vending. The original purpose of allowing street food vending was to help ensure food security. Currently, it is used for increasing informal employment as a response to unemployment caused by the COVID-19 pandemic. The temporary informalization is important for mitigating food insecurity, which demonstrates China's adaptability in contexts of crisis.

a * Corresponding author: Taiyang Zhong, Associate Professor, School of Geography and Ocean Science, Nanjing University; 163 Xianlin Avenue; Nanjing, Jiangsu Province, China 210023; taiyangzhong@163.com

b Steffanie Scott, Professor, Department of Geography and Environmental Management, University of Waterloo; 200 University Avenue West; Waterloo, Ontario N2L 3G1, Canada; sdscott@,uwaterloo.ca

\section{Funding Disclosure}

This research was funded by the Canadian Institutes of Health Research (CIHR) and the Social Sciences and Humanities Research Council of Canada (SSHRC).
\end{abstract}


$\mathrm{W}$ hile lockdown policies in South Africa in response to the COVID-19 epidemic have reinforced the bias against the informal food sector (Battersby 2020), which is considered less modern, China has recently adopted an opposite policy stance to promote the informal food sector, overturning regulations that had clamped down on street food vending in China over the past 25 years.

As of May 27, 2020, the Chinese central government required local governments to allow street food vending. ${ }^{1}$ In the months before the central government issued this requirement, some local governments such as Nanjing had already relaxed the implementation of regulations for street food vending. For instance, after the lifting (or degrading, to the second grade) of some quarantine measures for battling the COVID-19 epidemic, restaurants in Nanjing have been de facto allowed to sell their cooked food in front of residential neighborhoods.

The original purpose of this change in street food vending regulations was to help ensure food security - specifically food access_-due to the slow recovery of food retailing capacity in public markets. Public markets are the most important food retail outlets in China (Zhong, Si, Crush, Scott, \& Huang, 2019). Nanjing implemented quarantine measures for battling COVID-19 starting on January 24 , the day before the Chinese Spring Festival of 2020. More than half of food vendors in public markets in Nanjing are migrants to the city. Normally, most of these nonlocal food vendors operating inside public markets would go back to their hometown for the Spring Festival and return to work one week later. However, this year, nonlocal food vendors were required to self-quarantine for two weeks upon return to Nanjing, and some food vendors could not, or were reluctant to, return Nanjing because of travel restrictions. Therefore, the food retailing capacity in public markets was not as high as usual. The Nanjing Municipal Government intentionally relaxed the prohibition on street food vending in order to boost food access. Local authorities who patrol the streets (chenguan) turned a blind eye to street vending, which signaled tolerance and a relaxation of the prohibition. This flexible implementation somewhat alleviated the problem of having fewer vendors — and thus less supply—at public markets.

Allowing street vending at this time is not only used as a tool for improving food access, but also for increasing informal employment. By the end of May 2020, all the wet markets had returned to normal operations, and all nonlocal food vendors within public markets had returned to work. Thus, it was not solely to improve food access per se that street food vending was tacitly permitted. Rather, it was important for low-income households to earn an income from street food vending. According to our online survey, conducted in March, more than 20\% of surveyed households in Nanjing experienced income loss due to the COVID-19 pandemic. This affected the food security of some of these households. Therefore, the central government's policy of allowing street food vending not only encourages economic recovery but also will bolster food security in low-income households.

There are challenges regarding how to maintain physical distancing and ensure food safety for street food vending. Increasingly, a number of local governments have made some policies to address those challenges caused by informalization. Local government could find a good way to maintain the physical distancing of food vendors; however, it is not as easy to control the food safety risks posed by informalization. Thus, informalization is essentially a trade-off between food safety and employment promotion.

Local governments in China have made long-term efforts to formalize the informal food sector for the sake of food hygiene and safety. In the 1980s, most wet markets were informal roadside (outdoor) markets. Since the mid-1990s, local governments have made efforts to formalize these practices by building covered, open-air marketplaces and then building enclosed, indoor public marketplaces. Currently, most public markets in Nanjing are indoor, while the outdoor informal food sector instances make up a very small portion of the urban food system in the city. No matter how small, the informal food sector

1 See https://www.guancha.cn/politics/2020 $05 \quad 27$ 551945.shtml 
never disappeared in Nanjing (Dai, Zhong, \& Scott, 2019). There has been a flexible implementation of the regulation prohibiting street food vending for many years in Nanjing. The flexible implementation has been skillfully used as an informal means of compensating landless farmers who lost farmland due to land expropriation, as it has enabled them to conduct informal food vending instead (Dai et al., 2019). The ongoing plan (established prior to COVID-19) is to construct new public marketplaces to keep pace with urban population growth and to provide employment for more food vendors. The central government's current special permission granted for street food vending is temporary.

The temporary informalization demonstrates China's adaptability in contexts of crisis. Food vending could be the easiest way for low-income households to earn income in the context of the COVID-19 pandemic. Temporary “informalization” of food vending certainly bolsters low-income households' food security, which is worth the food safety risks posed by informalization. The COVID-19 pandemic has made the world uncertain, but the world certainly can mitigate food insecurity through adaptive governance, such as temporary informalization.

\section{References}

Battersby, J. (2020). South Africa's lockdown regulations and the reinforcement of anti-informality bias. Agriculture and Human Values. Advance online publication. https://doi.org/10.1007/s10460-020-10078-w

Dai, N., Zhong, T., \& Scott, S. (2019). From overt opposition to covert cooperation: Governance of street food vending in Nanjing, China. Urban Forum, 30(4), 499-518. https://doi.org/10.1007/s12132-019-09367-3

Zhong, T., Si, Z., Crush, J., Scott, S., \& Huang, X. (2019). Achieving urban food security through a hybrid public-private food provisioning system: The case of Nanjing, China. Food Security, 11(5), 1071-1086.

https://doi.org/10.1007/s12571-019-00961-8 